Int. J. Dev. Biol. 55: 981-987

doi: $10.1387 / \mathrm{ijdb} .103276 \mathrm{md}$

\title{
Hypoxia-inducible factor 1 controls the expression of the uncoordinated-5-B receptor, but not of Netrin-1, in first trimester human placenta
}

\author{
MBARKA DAKOUANE-GIUDICELLI*,1, NADIA ALFAIDY², PERRINE BAYLE ${ }^{1}$, \\ ALEXANDRETASSIN DE NONNEVILLE ${ }^{1}$, VIVIEN STUDER ${ }^{1}$, PATRICK ROZENBERG ${ }^{3}$ \\ and PHILIPPE DE MAZANCOURT ${ }^{1}$

\begin{abstract}
${ }^{1}$ Université de Versailles-St Quentin (UVSQ), Service de Biochimie et Biologie Moléculaire, UPRES-EA 2493, UFR Paris-lle de France Ouest, PRES Universud Paris, Centre Hospitalier de Poissy-Saint Germain, Poissy, France,
\end{abstract} \\ ${ }^{2}$ CEA Grenoble, iRTSV /LAPV, Grenoble, France and ${ }^{3}$ Service de Gynécologie-Obstétrique, Poissy France
}

\begin{abstract}
Uncoordinated-5 homologs 1-4 (UNC5H1-4) transmembrane netrin receptors are reported to control a number of cellular processes, including axonal guidance, angiogenesis and cell proliferation. These receptors are known as "dependence receptors" because they are able to induce apoptosis in the absence of their ligand, netrin. We have recently reported the localization of netrin-1 and its uncoordinated-5-B (UNC5B) receptor in both villous and extravillous cytotrophoblasts in the human placenta. However, the roles that netrin-1 and UNC5B play in the development of the placenta, as well as the regulation of their expression during the early stages of placental development, remain unexplored. Placental explants were used to demonstrate a proliferative effect of netrin-1 on cytotrophoblasts, as assessed by Ki67 staining. Primary cytotrophoblasts collected at different gestational ages during the first trimester of pregnancy indicated that netrin-1 mRNA expression decreased after 6 weeks of gestation $(\mathrm{wg}$ ), whereas UNC5B expression increased gradually up to 13-14 wg. The BeWo cell line was used to evaluate the effect of hypoxia on the expression of netrin-1 and UNC5B. Primary cytotrophoblast and BeWo cells cultured under hypoxic conditions exhibited a decrease in the expression of UNC5B both at the mRNA and protein levels; in contrast, hypoxia induced no change in the levels of netrin-1. When hypoxia-inducible factor $1 \alpha$ (HIF-1 $\alpha$ ) was knocked down by siRNA, we found a significant increase in UNC5B expression, indicating that the HIF-1 pathway is involved in hypoxia-induced UNC5B transcriptional down-regulation. Altogether, these results demonstrate the role of netrin-1 as a new mitogenic factor for cytotrophoblastic cells, report the pattern of expression of netrin-1 and its receptor, UNC5B, in the human placenta during the first trimester of pregnancy, and bring insights into the direct control of the expression of UNC5B by HIF-1.
\end{abstract}

KEY WORDS: human placenta, hypoxia, UNC5B, Netrin-1, HIF-1

Netrin and netrin receptors are widely expressed in various mammalian embryonic and adult tissues (Engelkamp 2002). These proteins are reported to control a number of cellular processes such as axonal guidance, angiogenesis, morphogenesis, proliferation and apoptosis (Cirulli and Yebra 2007; Llambi et al., 2001; Matilanien et al., 2007). Netrin-1 has been proposed to play a role in tumorigenesis through the regulation of apoptosis. This survival activity is mediated via the inhibition of netrin-1 dependence receptors DCC (Deleted in Colorectal Cancer) and UNC5H (uncoordinated-5-homolog).

Of all the proteins in the netrin and UNC5 families, netrin-1 and UNC5B are the most extensively studied. We have recently characterized the expression of netrin-1 and its UNC5B receptor in the human placenta during the first and last trimesters of

Abbreviations used in this paper: DCG, deleted in colorectal cancer; HIF, hypoxiainducible factor; siRNA, small interfering RNA; UNC5B, uncoordinated-5-B; UNC5H, uncoordinated-5-homolog; wg, weeks of gestation.

\footnotetext{
*Address correspondence to: Mbarka Dakouane-Giudicelli. EA2493, Laboratoire de Biologie, CHI de Poissy, 9 rue du Champ Gaillard, 78303 Poissy Cedex, France. Fax: +33-1-39-27-54-66. E-mail: dakouane@ hotmail.com
} 
pregnancy. Both Netrin-1 and UNC5B were expressed in villous cytotrophoblasts, suggesting an autocrine regulatory mechanism in these cells which might be mediated by netrin-1 (DakouaneGiudicelli et al., 2010).

Disruption of one netrin allele, or of its $\mathrm{UNC5H}$ receptors, is lethal during early embryogenesis in mice, suggesting a crucial role for netrin-1 and its UNC5H receptors in this process (Navankasattusas et al., 2008; Rabe et al., 2009). As was mentioned above, netrin-1 and UNC5B have been shown to control angiogenesis and vasculogenesis, two essential processes for a successful placentation during the first trimester of pregnancy.

Recently, netrin-1 was shown to increase proliferation in the trophoblast TVE cell line through its neogenin and UNC5B receptors (Yang etal., 2009). However, to date, neither the direct involvement of netrin- 1 in cytotrophoblast proliferation in a physiological model such as the placental explant, nor the determination of its pattern of expression and that of its UNC5B receptor have been examined. Furthermore, the regulation of their expression by hypoxia during early placental development also remains unexplored.

The human placenta undergoes a transition from a low oxygenated to a highly oxygenated environment during the first trimester of pregnancy. This physiological switch in oxygen tension is a prerequisite for proper placental development and involves the hypoxia-inducible factor (HIF-1), a protein that is up-regulated under hypoxic conditions. HIF-1 modulates gene transcription by binding to a specific DNA sequence known as the hypoxic response element (HRE). HIF-1 is a heterodimer composed of HIF-1 $\alpha$ and HIF- $1 \beta$ subunits; HIF- $1 \beta$ is generally constitutively expressed and insensitive to changes in $\mathrm{O}_{2}$ availability, whereas HIF- $1 \alpha$ is acutely regulated in response to hypoxia (Ozaki et al., 1999).
Before 11 weeks of gestation (wg), placental oxygen remains low and is equivalent to $2-3 \%$, which appears to be necessary to allow for specific placental metabolic activities, and to protect both placental and fetal tissues against toxic oxygen metabolites (Jauniaux et al., 2001; Illsley et al., 2010). An increase in the oxygen level occurs around 10 to $12 \mathrm{wg}$ (Rodesch et al., 1992), when a continuous maternal blood flow is established in the intervillous space.

In fact, in the first trimester placenta, HIF-1 $\alpha$ is expressed in syncytiotrophoblasts and in villous cytotrophoblasts (Rajakumar and Conrad, 2000). A study by letta et al., showed that HIF-1 $\alpha$ mRNA and protein peaked at 7-10 weeks of gestation, when the oxygen tension is low, and declined thereafter (letta et al., 2006). In the present study we investigated the role of netrin-1 in placental development by determining its effect on the proliferation of trophoblasts in an organotypic model, the placental explant. Furthermore, we examined netrin-1 and UNC5B expression in primary trophoblast cells that have been isolated from placentas collected at different gestational ages during the first trimester of pregnancy, and determined the regulation of UNC5B expression by oxygen tension, as this parameter changes from very low to high levels during this period of placental development. BeWo cells were also used to determine the mechanisms by which hypoxia regulates netrin-1 and UNC5B gene transcription.

\section{Results}

\section{Proliferation}

Previous data from our group showed that villous cytotrophoblasts express netrin-1 and possess UNC5B, but not DCC, receptors. To investigate the effect of netrin-1 on trophoblast proliferation, we used Ki67 staining of placental explants from first trimester placentas. It was particularly relevant to study netrin- 1 effects in an organotypic system in which villous tissue architecture is maintained. Placental villous explant in culture preserves the topology of intact villi and mimics its physiological responses. The addition of exogenous netrin-1 to villous explants exhibited an increase in the index of cytotrophoblast proliferation by significantly increasing the Ki67 stained nuclei at $50 \mathrm{ng} /$ $\mathrm{ml}$ and $100 \mathrm{ng} / \mathrm{ml}$ (Fig. 1).

\section{Pattern of expression of Netrin-1 and UNC5B mRNA during the first trimester}

We investigated the ontogeny of netrin-1 and UNC5B mRNA expression during the first trimester by exploring their content in cytotrophoblast cells isolated from placentas at different gestational ages (6 to $14 \mathrm{wg}$ ).

Fig. 1. Effect of exogenous netrin-1 on villous explants using Ki67 nuclear marker of proliferation. $(\mathbf{A}, \mathbf{B})$ Immunohistochemical detection of Ki67 in villous cytotrophoblast cells. (A) note the increase Ki67 immunolabeled cells in the presence of exogenous netrin-1 with increase number of cytotrophoblast cells compared to control condition in the absence of exogenous netrin-1 (B). (C) Quantification of Ki67

nuclear immunostaining in villous explants from first trimester placenta cultured in matrigel for $48 \mathrm{~h}$. Note a significant increase of cytotrophoblast proliferation was observed in the presence of recombinant netrin-1 $\left(^{*} p<0.05\right)$. Data represent the mean of 4 experiments $+/-S E M$.
As shown in Fig. 2A, netrin-1 mRNA expression decreased in cytotrophoblast cells with increasing gestational age during the first trimester, the expression at 6 weeks being more than twice the level found in cytotrophoblast cells from 9 to $14 \mathrm{wg}$ placentas. Conversely, mRNA expression of UNC5B remained weak in cytotrophoblast cells through 6 to $11 \mathrm{wg}$ but increased 4-fold 
Fig. 2. Expression and ontogeny of netrin-1 and UNC5B mRNA in human first trimester placenta. (A) netrin-1 expression normalized to placenta at $6 \mathrm{wg}$ demonstrating a decrease in netrin-1 mRNA expression with gestational age, (B) UNC5B expression normalized to placenta at $6 \mathrm{wg}$ demonstrating increase in UNC5B mRNA expression with gestational age. The graph shows mean +/- SEM, where $n$ represents the number of placenta analyzed for each gestational age.
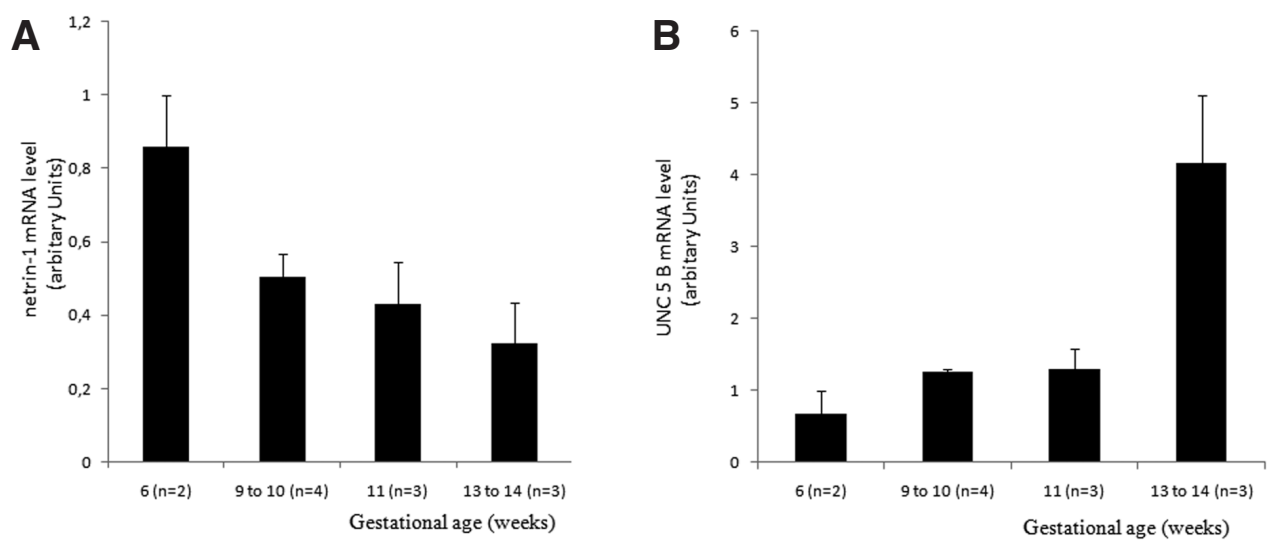

at 13 to $14 \mathrm{wg}$, compared to cells at 6 to $11 \mathrm{wg}$ (Fig. 2B).

\section{Netrin-1 and UNC5B expression in cytotrophoblast cells and BeWo cells under conditions of hypoxia}

To gain more insight into the causes that underlie these opposite patterns in netrin-1 and UNC5B mRNA expression, we first tested the influence of hypoxia $\left(2 \% \mathrm{O}_{2}\right)$ on netrin-1 and UNC5B gene expression in villous cytotrophoblast cells and in their surrogate BeWo cells. BeWo cells were first tested for the expression of netrin- 1 and UNC5B protein and transcripts. Using RT-PCR and immunocytochemistry, we demonstrated that BeWo cells are indeed netrin-1 and UNC5B expressing cells (Fig $3 \mathrm{~A}, \mathrm{~B}, \mathrm{E}$ ). By using quantitative RT-qPCR using SYBR green and normalized to TBP and $\beta 2 \mathrm{M}$ our results showed that netrin-1 mRNAwas expressed more abundantly in BeWo cells (9-fold) in comparison to primary cytotrophoblast cells. UNC5B mRNA was similarly expressed in BeWo cells and in primary cytotrophoblast cells (Fig. 3F).

\section{HIF-1 $\alpha$ expression in BeWo cells under conditions of hypoxia}

To validate our model of hypoxia it was necessary to demonstrate that HIF- $1 \alpha$ mRNA expression is upregulated under our experimental conditions. Thus, HIF-1 $\alpha$ expression in BeWo cells was examined by quantitative RT-PCR. The results showed that the level of HIF-1 $\alpha$ mRNA was up-regulated two-fold after 6 hours of hypoxia and returned to the baseline levels after 24 hours. These results indicate that HIF-1 $\alpha$ mRNA is up-regulated by hypoxia in BeWo cells, like in many other cell types, and validates our experimental conditions of hypoxia (Fig. 4C).

The effect of hypoxia on UNC5B and Netrin-1 expression in cytotrophoblast cells and in BeWo cells

The incubation of primary cytotrophoblast cells under hypoxia for 24 hours resulted in a $22 \pm 1 \%$ (Fig. 4B) decrease in UNC5B mRNA expression as assessed by relative quantification by $2^{-\Delta \Delta C p}$ method. As shown in Fig. 4E, the exposure of BeWo cells to conditions of hypoxia for 24 hours or 48 hours resulted in a strong down-regulation (48 $10 \%)$ of UNC5B as well. Down-regulation of UNC5B expression was
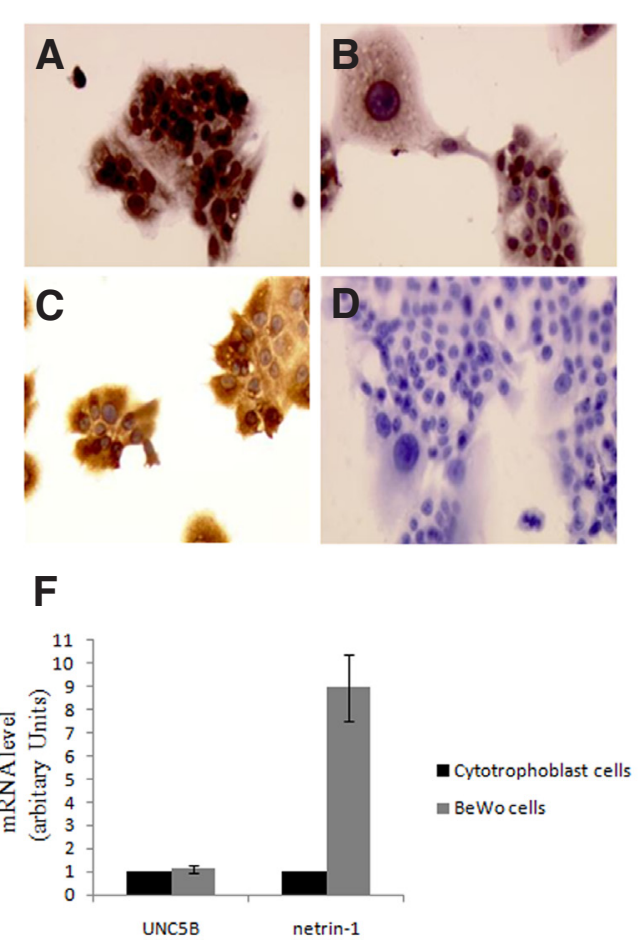

Fig. 3. Characterization and expression of netrin-1 and its UNC5B receptor in BeWo cells. (A) Goat anti-netrin-1 immunoreactivity was found in BeWo cells. (B) Goat antiUNC5B immunoreactivity was found in BeWo cells. (C) Mouse anti-cytokeratin 7 showing immunoreactivity in BeWo cells. (D) Negative control processed in the absence of primary antibody. (E) Gel electrophoresis and ethidium bromide staining of netrin-1 and UNC5B, RT-PCR products from purified mRNA of BeWo cells. Note the presence of one PCR product at the expected size. $(\mathbf{F}) \cup N C 5 B$ and netrin-1 mRNA relative quantification using the $2^{-\triangle A C P}$ method relative to level of houskeping gene TBP and $\beta 2 \mathrm{M}$ determined using comparative cycle: crossing point ( $\mathrm{CP}$ ) in BeWo cells cultured under conditions of normoxia normalized to UNC5B and netrin-1 expression in villous cytotrophoblast cells isolated from placenta before $11 \mathrm{wg}$. The graph show that netrin-1 mRNA was expressed more abundantly in BeWo cells (9-fold) in comparison to primary cytotrophoblast cells whereas UNC5B mRNA was similarly expressed in BeWo cells and in primary cytotrophoblast cells. 

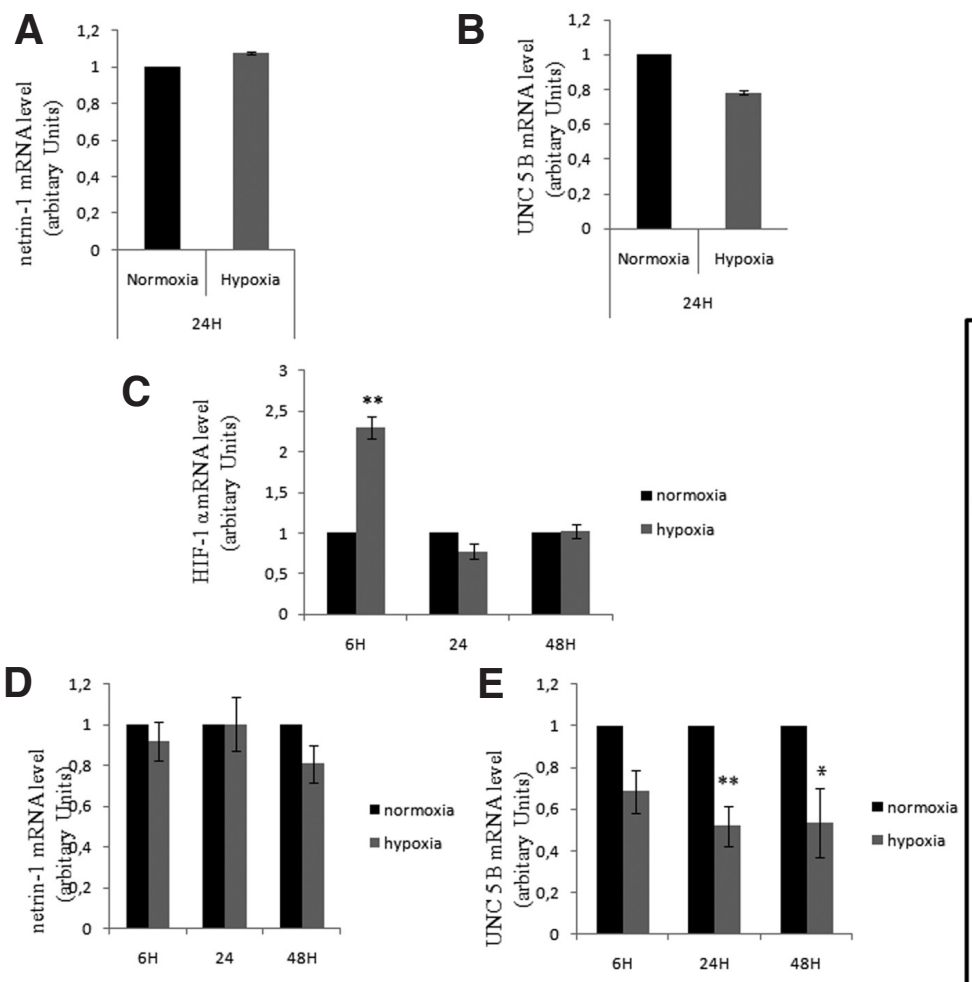

Fig. 4. Effect of hypoxia on netrin-1, UNC5B and HIF-1 $\alpha$ expression. (A,B) In primary cytotrophoblast cells hypoxia induces down-regulation of UNC5B (B) mRNA expression but not of netrin-1 (A). (C) In BeWo cells hypoxia induces up-regulation of HIF-1 $\alpha$ mRNA by two-fold after 6 hours and then returns to the baseline profile. (D,E) In BeWo cells note that hypoxia induces Down-regulation of UNC5B (E), but not of netrin-1 (D). Confirmation of UNC5B down-regulation by Western blotting (F). Data represent the mean of 5 experiments $+/-$ SEM ${ }^{*} p<0.05,{ }^{* *} p<0.01$.

with specific siRNA. As shown in Fig. 5A, under conditions of hypoxia $\left(2 \% \mathrm{O}_{2}\right)$, HIF- $1 \alpha$ suppression resulted in an $80 \% \mathrm{HIF}-1 \alpha$ gene silencing. In parallel, we observed a two-fold increase in UNC5B mRNA expression (Fig. 5C). These results demonstrate that UNC5B gene transcription is under the control of the HIF1 pathway. These results were substantiated at the protein level as shown on the western blot (Fig. 5D).

\section{Discussion}

The present findings demonstrate for the first time that UNC5B expression is down-regulated by hypoxia both in villous cytotrophoblast cells and in BeWo cells cultured under conditions of hypoxia. We found that UNC5B mRNA in villous cytotrophoblast cells is decreased at 6-11 $\mathrm{wg}$, when oxygen tension is low, and then increased gradually until reaching peak expression at 13-14 wg, when the blood flow is established and oxygen tension increases in the intervillous space. Villous cytotrophoblast cells cultured under conditions of hypoxia exhibited significant lower levels of UNC5B transcript and protein when compared to normoxia. Our in vitro experiments established that hypoxia is an inhibitor of UNC5B expression. Consistent with this observation, it has been reported that in solid tumors, where hypoxia is essential for the growth of the tumor, there is also a loss of, or a reduction in, the expression of UNC5B. The decreased UNC5B expression leads to a reduction of pro-apoptotic activity and consequently provides an advantage

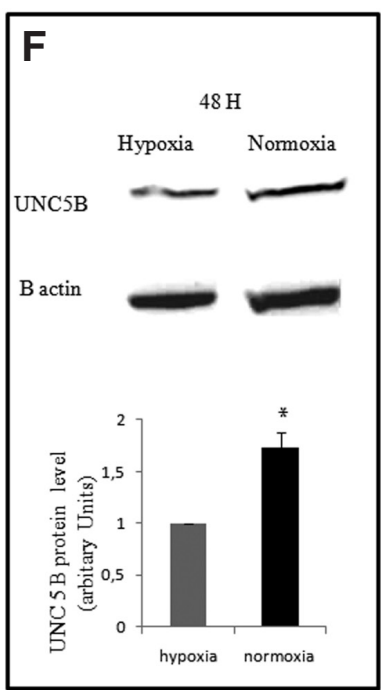

for the growth of tumors (Thiebault et al., 2003). Here, we show a similar pattern of UNC5B gene expression with a dependence on oxygen tension throughout the first trimester of pregnancy. We found that the changes in UNC5B expression correlate with the changes in oxygen tension. Conversely to UNC5B expression, netrin-1 was strongly expressed at $6 \mathrm{wg}$ and its expression subsequently decreased with advancing gestational age. The placenta at $6 \mathrm{wg}$ is characterized by a high cytotrophoblastic proliferation rate (Huppertz et al., 1998). Here we demonstrated for the first time that the highest levels of netrin-1 expression are found during this period of gestation (6 wg), and we provide the evidence for the direct involvement of this protein in the proliferation of cytotrophoblast cells. Altogether, these findings show a negative correlation between the rates of expression of UNC5B and netrin-1. Netrins and their receptors have been proposed to play role in tumorigenesis by regulating apoptosis. In fact, it was reported that most colorectal tumors are associated with a loss of dependence receptors, or a gain of netrin-1 (Llambi et al., 2001). In vitro overexpression of the wild-type UNC5B in either COS7 or HEK293T cells significantly enhanced the apoptosis of transfected cells (Wang et al., 2009). Here, we found a resemblance between villous cytotrophoblast from early first trimester placenta and solid tumors at their netrin-1 and UNC5B transcriptional activities. In the placenta, the incidence of apoptosis in villous cytotrophoblast cells increased with gestational age (Smith et al., 1997), which correlates with the increase in UNC5B levels. The increase in UNC5B levels coincides with the oxygenation of the placenta and with the initiation of physiological cytotrophoblast apoptosis. Thus, our results suggest a physiological significance in placental development during the first trimester of pregnancy, when proliferation and apoptosis control most of the placentation processes.

In this work we confirmed the up-regulation of HIF-1 $\alpha$ mRNA expression by a factor of two after 6 hours of hypoxia and a reversion to the baseline level at 24 hours, suggesting a regulation of HIF-1 $\alpha$ mRNA by prolonged hypoxia. Consistent with this, other studies have reported that HIF- $1 \alpha$ mRNA in the brain, kidney and lung of rats and mice was up-regulated within $30 \mathrm{~min}$ and returned to baseline level after 4 hours (Wiener et al.,1996). On the other hand, a knockdown of HIF-1 $\alpha$ using siRNAs under hypoxia induced an increase in UNC5B mRNA and protein expression, providing evidence that UNC5B down-regulation is mediated through the HIF-1 pathway.

In conclusion, our results elucidate the pattern of expression of 


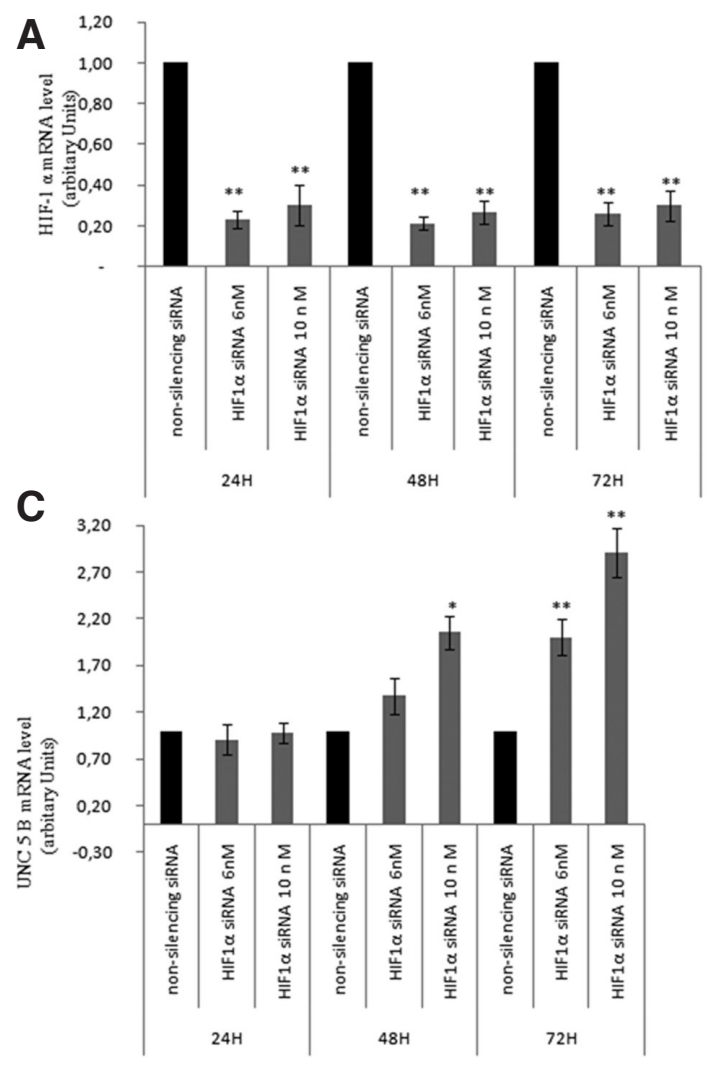

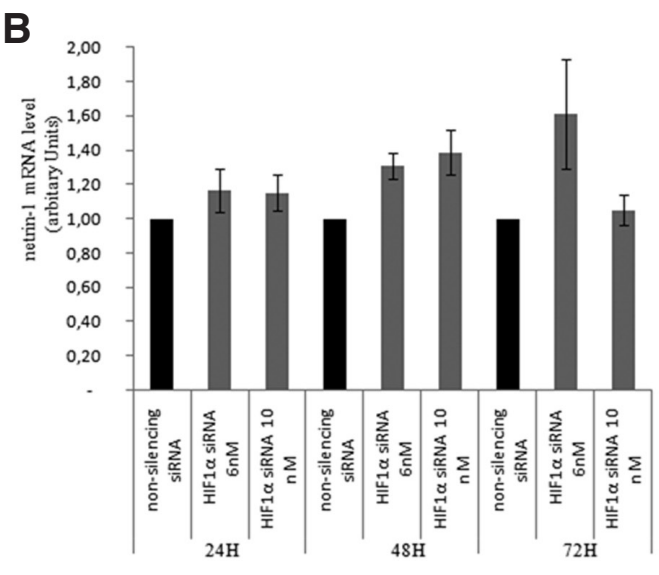

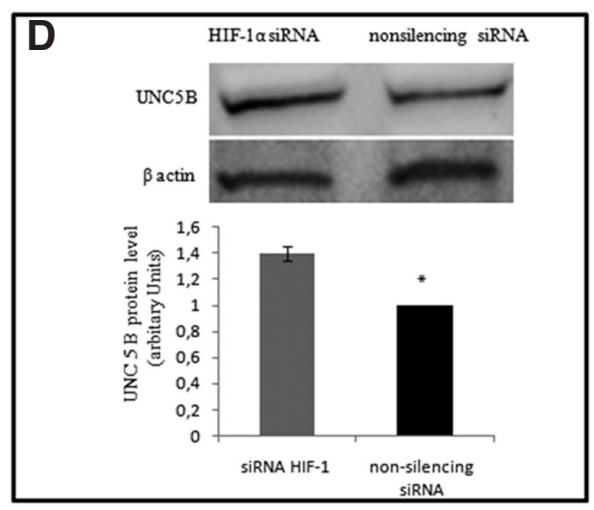

Fig. 5. Inhibition of HIF-1 $\alpha$ with siRNA induces a reverse inhibitory effect of UNC5B. (A) HIF-1 $\alpha$ with SiRNA (6 nM or $10 \mathrm{nM}$ ) abolishes HIF-1 $\alpha$ mRNA expression. (B) No significant change in netrin-1mRNA expression. (C) Significant increase in response to HIF-1 $\alpha$ inhibition by SiRNA HIF-1 $\alpha$ with reverses of inhibitory effect of hypoxia on UNC5B $m R N A$ note increase amount up to 3 fold. (D) UNC5B protein level is also increased after HIF-1 $\alpha$ siRNA transfection in BeWo cells under hypoxia. Control cells were transfected with non-silencing siRNA. Data represent the mean of 6 experiments +/-SEM $\left({ }^{*} p<0.05,{ }^{*} p<0.01\right)$. netrin-1 and lend support for its direct involvement in the proliferation of trophoblasts. Moreover, our data demonstrate for the first time that UNC5B receptor expression is down-regulated by hypoxia in the human placenta during the first trimester of pregnancy, and that its regulation is under the direct control of HIF-1. The description of proliferative capacities in early placenta (6-10 wg) associated to high netrin-1 expression and the increased Ki67 staining described here is in favor of a proliferative netrin- 1 effect at this stage. These data leave open the question of the receptor(s) such as neogenin, other UNC5 family members or members of integrin family, involved in the proliferative effect of netrin-1. A role of UNC5B in the proliferative/apoptotic balance is possible since UNC5B has been shown to mediate p53 dependent apoptosis (Tanikawa et al., 2003). These data bring new insights and questions to the regulation of placental development during the first trimester of pregnancy. This work represents a starting point for the study of netrin-1 and UNC5B in the placenta. By understanding gene regulation in the normal placenta, we can get more insight into their deregulation in placental diseases. Collectively, these findings highlight a new mechanism for the hypoxic inactivation of UNC5B via HIF-1 and the putative consequences on the proliferative/apoptotic balance.

\section{Materials and Methods}

\section{Collection of samples}

Informed consent was obtained in writing from all participants in this study. Placental villous tissue was collected on an anonymous basis from 12 healthy women with viable singleton ultrasound-dated pregnancies who were undergoing an elective termination of pregnancy procedure at between 6 and 14 weeks of gestation $(\mathrm{wg})$.

\section{Isolation and treatment of cytotrophoblasts}

Isolation and treatment of cytotrophoblasts were performed as described by (Dakouane-Giudicelli et al., 2010). Then cytotrophoblasts were RNA extracted or seeded at a density of 150,000 cells $/ \mathrm{cm}^{2}$ in DMEM, 10\% fetal bovine serum, $100 \mathrm{IU}$ penicillin, $5 \mu \mathrm{g} / \mathrm{mL}$ gentamycin and $10 \mu \mathrm{g} /$ $\mathrm{mL}$ streptomycin. After 24 hours of culture at $37^{\circ} \mathrm{C}$ in $5 \% \mathrm{CO}_{2}, 95 \%$ air, cytotrophoblasts were then cultured for 24 hours at $37^{\circ} \mathrm{C}$ in $5 \% \mathrm{CO}_{2}$, $95 \%$ air or at $37^{\circ} \mathrm{C}$ in $2 \%$ O2, $5 \% \mathrm{CO}_{2}, 93 \% \mathrm{~N}_{2}$.

\section{Culture of villous fragments and immunohistochemistry}

To prepare the serial sections of explants, we cultured villous fragments on matrigel. Placental explants were cultured for 48 hours on matrigel under either the absence or presence of different doses of exogenous netrin-1. Each set of conditions was fixed for $24 \mathrm{~h}$ at room and temperature in $4 \%$ ( $\mathrm{vol} / \mathrm{vol})$ paraformaldehyde, and immunolabled as described by (Dakouane-Giudicelli et al., 2010) with the commercial primary antibody against Ki67 (Dako) at 1:60 for 28 minutes at room temperature. Villous cytotrophoblast nuclei labeled positively for Ki-67 were counted in three or more villous section by using a computerassisted morphometric (Histolab version 5.2.3; Microvision Instrument, Paris, France). The result was expressed as mean number of labeled nuclei of villous cytotrophoblast per surface area $(80000 \mu \mathrm{m} 2)$ of placental villous.

\section{Netrin-1 and UNC5B immunocytochemistry of BeWo cells}

BeWo cells were cultured in LabTek for $48 \mathrm{~h}$, after washing in phosphate-buffered saline solution and fixation in methanol for $5 \mathrm{~min}$. the primary antibodies used were polyclonal goat anti-N-terminal netrin-1 (Santa Cruz biotechnology, Santa Cruz CA, USA, dilution 1:50), rabbit anti- C-terminal netrin-1 (Santa Cruz, dilution 1:50), goat antiUNC5B (Santa Cruz, dilution 1:50) for $30 \mathrm{~min}$, or mouse monoclonal anti-cytokeratin 7 (Dako Cytomaton, Glostrup, Denmark) for $30 \mathrm{~min}$, 
TABLE 1

\section{PRIMER SEQUENCES}

\begin{tabular}{|c|c|c|c|c|c|}
\hline Gene & Accession number and location & primer & Sequence & Product size (base pair) & $\operatorname{Tm}^{\circ} \mathrm{C}$ \\
\hline Netrin-1 & $\begin{array}{l}\text { NM_004822 } \\
1505-1609\end{array}$ & $\begin{array}{l}\text { Forward } \\
\text { Reverse }\end{array}$ & $\begin{array}{l}\text { GTGGAGGAGCCTGAAGACTG } \\
\text { GTGGATCTGGACGGCATAGT }\end{array}$ & 105 & 60 \\
\hline UNC5B & $\begin{array}{l}\text { NM_170744 } \\
1669-1830\end{array}$ & $\begin{array}{l}\text { Forward } \\
\text { Reverse }\end{array}$ & $\begin{array}{l}\text { CCACCCCGTCAACTTTAAGA } \\
\text { TCCAGCAGAGGAGAGTTGGT }\end{array}$ & 162 & 60 \\
\hline HIF- $1 \alpha$ & $\begin{array}{l}\text { NM_181054.2 } \\
815-1065\end{array}$ & $\begin{array}{l}\text { Forward } \\
\text { Reverse }\end{array}$ & $\begin{array}{l}\text { TCCATGTGACCATGAGGAAA } \\
\text { CCAAGCAGGTCATAGGTGGT }\end{array}$ & 251 & 58 \\
\hline TBP & $\begin{array}{l}\text { NM_003194.3 } \\
893-1024\end{array}$ & $\begin{array}{l}\text { Forward } \\
\text { Reverse }\end{array}$ & $\begin{array}{l}\text { TGACAGGAGCCAAGAGTGAA } \\
\text { CACATCACAGCTCCCCACCA }\end{array}$ & 132 & 60 \\
\hline B2M & $\begin{array}{l}\text { NM_004048.2 } \\
589-674\end{array}$ & $\begin{array}{l}\text { Forward } \\
\text { Reverse }\end{array}$ & $\begin{array}{l}\text { TGCTGTCTCCATGTTTGATGTATCT } \\
\text { TCTCTGCTCCCCACCTCTAAGT }\end{array}$ & 86 & 60 \\
\hline
\end{tabular}

which was used as a marker for epithelial cells. As negative controls, LabTek slides were processed as above but in the absence of the primary antibody and in presence of normal rabbit IgG, normal mouse IgG (BioGenex, San Ramon, CA) and normal goat IgG (Santa Cruz).

\section{Culture of choriocarcinoma BeWo cell line under hypoxic and nor- moxic conditions}

BeWo choriocarcinoma cells (ATCC Rockville, MD, USA) were plated at a density of $2.10^{5} \mathrm{cells}$ on a $35 \mathrm{~mm}$ dish in $2 \mathrm{ml}$ DMEM/ F-12 Ham (Sigma-Aldrich) containing 15\% fetal bovine serum, $100 \mathrm{IU}$ penicillin and $10 \mu \mathrm{g} / \mathrm{mL}$ streptomycin. After 24 hours, cells were cultured under normoxic $\left(20 \% \mathrm{O}_{2}\right)$ or hypoxic $\left(2 \% \mathrm{O}_{2}\right)$ conditions for 6 hours, 24 hours or 48 hours $\left(2 \% \mathrm{O}_{2}\right.$ is close to the physiological $\mathrm{O}_{2}$ tension that is present during early pregnancy).

\section{HIF-1 $\alpha$ knockdown induced by small interfering RNA (siRNA) in choriocarcinoma BeWo cell line}

Two hundred thousand BeWo cells were plated in a $35 \mathrm{~mm}$ dish in $2 \mathrm{ml}$ DMEM/ F-12 Ham containing 15\% fetal bovine serum without antibiotics. Cells were grown up to $40-50 \%$ confluency and then transfected with HIF-1 $\alpha$ specific siRNA oligonucleotides (Santa Cruz biotechnology, Santa Cruz CA, USA) or with fluorescently-labeled negative control siRNAs, using Lipofectamine ${ }^{\text {TM }}$ RNAiMAX (Invitrogen Carlsbad, CA, USA) for 24 hours, 48 hours and 72 hours.

\section{RNA isolation and RT-PCR analysis}

RNA extraction, RNA quantification and reverse Transcription were performed as described by (Dakouane-Giudicelli et al., 2010), followed by quantitative PCR using syber green detection on light cycler 480 (Roche Light Cycler 480, Mannheim, Germany) using the primers described in Table 1.

The data were analyzed using the $2^{-\Delta \Delta C_{p}}$ method. Fold changes in netrin-1 and UNC5B expressions were established relative to the TBP (TATA-binding protein) and $\beta 2$ microglobulin housekeeping genes under the various experimental conditions used.

\section{Western blot analysis}

Western blot analysis was performed as described by (DakouaneGiudicelli et al., 2010) with goat anti-UNC5B (1:200) or with mouse anti-9-actin (1:100; Santa Cruz biotechnology) for standardization. Blots were then rinsed three times with TBS-T and incubated with the appropriate anti-lgG (horseradish peroxydase-linked antirabbit IgG for 9-actin 1:5000 or horseradish peroxydase-linked antigoat IgG for antiUNC5B 1:10000) in TBS for 1 hour. Finally, the blots were washed three times with TBS-T, and the antibody-antigen complexes were detected using the enhanced chemiluminescence detection system (Amersham Pharmacia Biotech). Membrane chemiluminescence was captured using the FX7 image acquisition system with cooled CCD technology (Vilber-Lourmat, Marne-la-Vallée, France). Data produced by the Fusion FX7 were analyzed using Bio-1D software.

\section{Statistical analysis}

All values were expressed as mean \pm SEM of 4 to 6 separate experiments, and statistical analysis was performed using the non-parametric paired Wilcoxon test.

\section{Acknowledgement}

We thank J Fortemps for technical assistance and Dr M Tetegan for her help with photography. This work was supported by grant BQR 2009 from UVSQ.

\section{References}

CIRULLI, V., and YEBRA, M. (2007). Netrins: beyond the brain. Nat Rev Mol Cell Biol 8: 296-306.

DAKOUANE-GIUDICELLI, M., DUBOUCHER, C., FORTEMPS, J., MISSEY-KOLB, H BRULE, D., GIUDICELLI, Y., and DE MAZANCOURT, P. (2010). Characterization and expression of netrin-1 and its receptors UNC5B and DCC in human placenta. $J$ Histochem Cytochem 58: 73-82.

ENGELKAMP, D. (2002). Cloning of three mouse Unc5 genes and their expression patterns at mid-gestation. Mech Dev 118: 191-197.

HUPPERTZ, B., FRANK, H. G., KINGDOM, J. C., REISTER, F., and KAUFMANN, P. (1998). Villous cytotrophoblast regulation of the syncytial apoptotic cascade in the human placenta. Histochem Cell Biol 110: 495-508.

IETTA, F., WU, Y., WINTER, J., XU, J., WANG, J., POST, M., and CANIGGIA, I. (2006). Dynamic HIF1A regulation during human placental development. Biol Reprod 75: 112-121.

ILLSLEY N. P., CANIGGIA I. and ZAMUDIO S. (2010). Placental metabolic reprogramming: do changes in the mix of energy-generating substrates modulate fetal growth? Int J Dev Biol. 54: 409-419.

JAUNIAUX, E., WATSON, A., and BURTON, G. (2001). Evaluation of respiratory gases and acid-base gradients in human fetal fluids and uteroplacental tissue between 7 and 16 weeks' gestation. Am J Obstet Gynecol 184: 998-1003.

LEONARDO, E. D., HINCK, L., MASU, M., KEINO-MASU, K., ACKERMAN, S. L., and TESSIER-LAVIGNE, M. (1997). Vertebrate homologues of C. elegans UNC-5 are candidate netrin receptors. Nature 386: 833-838.

LLAMBI, F., CAUSERET, F., BLOCH-GALLEGO, E., and MEHLEN, P. (2001). Netrin-1 acts as a survival factor via its receptors UNC5H and DCC. EMBOJ20:2715-2722.

MATILAINEN T., HAUGAS M., KREIDBERG J. A. and SALMINEN M. (2007). Analysis of Netrin 1 receptors during inner ear development. Int J Dev Biol. 51: 409-413.

NAVANKASATTUSAS, S., WHITEHEAD, K. J., SULI, A., SORENSEN, L. K., LIM, A H., ZHAO, J., PARK, K. W., WYTHE, J. D., THOMAS, K. R., CHIEN, C. B., and LI, D. Y. (2008). The netrin receptor UNC5B promotes angiogenesis in specific vascular beds. Development 135: 659-67.

OZAKI, H., YU, A. Y., DELLA, N., OZAKI, K., LUNA, J. D., YAMADA, H., HACKETT, S. F., OKAMOTO, N., ZACK, D. J., SEMENZA, G. L., and CAMPOCHIARO, P. A (1999). Hypoxia inducible factor-1alpha is increased in ischemic retina: temporal and spatial correlation with VEGF expression. Invest Ophthalmol Vis Sci 40: 182-189.

RABE, N., GEZELIUS, H., VALLSTEDT, A., MEMIC, F., and KULLANDER, K. (2009). Netrin-1-dependent spinal interneuron subtypes are required for the formation of left-right alternating locomotor circuitry. J Neurosci 29: 15642-15649. 
RAJAKUMAR, A., and CONRAD, K. P. (2000). Expression, ontogeny, and regulation of hypoxia-inducible transcription factors in the human placenta. Biol Reprod 63: 559-569.

RODESCH, F., SIMON, P., DONNER, C., and JAUNIAUX, E. (1992). Oxygen measurements in endometrial and trophoblastic tissues during early pregnancy. Obstet Gynecol 80: 283-5.

SMITH, S. C., BAKER, P. N. and SYMONDS, E. M. (1997). Placental apoptosis in normal human pregnancy. Am J Obstet Gynecol 177: 57-65.

TANIKAWA, C., MATSUDA, K., FUKUDA, S., NAKAMURA, Y. and ARAKAWA H. (2003). p53RDL1 regulates p53-dependent apoptosis. Nat Cell Biol. 5: 216-23.
THIEBAULT, K., MAZELIN, L., PAYS, L., LLAMBI, F., JOLY, M. O., SCOAZEC, J. Y., SAURIN, J. C., ROMEO, G. and MEHLEN, P. (2003). The netrin-1 receptors UNC5H are putative tumor suppressors controlling cell death commitment. Proc Natl Acad Sci USA 100: 4173-8.

WANG, R., WEI, Z., JIN, H., WU, H., YU, C., WEN, W., CHAN, L. N., WEN, Z., and ZHANG, M. (2009). Autoinhibition of UNC5b revealed by the cytoplasmic domain structure of the receptor. Mol Cell 33: 692-703.

YANG, Y., WANG, Y., DU, Y., ZHU, J. W., GAO, H., and ZOU, L. (2009). [Correlation of netrin-1 expression with invasion of extra villous trophoblasts]. Zhonghua $F u$ Chan Ke Za Zhi 44: 131-4. 


\section{Further Related Reading, published previously in the Int. J. Dev. Biol.}

Development of a fast, objective, quantitative methodology to monitor angiogenesis in the chicken chorioallantoic membrane during development

Eva Verhoelst, Bart De Ketelaere, Veerle Bruggeman, Eduardo Villamor, Eddy Decuypere and Josse De Baerdemaeker Int. J. Dev. Biol. (2011) 55: 85-92

Placental metabolic reprogramming: do changes in the mix of energy-generating substrates modulate fetal growth? Nicholas P. Illsley, Isabella Caniggia and Stacy Zamudio Int. J. Dev. Biol. (2010) 54: 409-419

Gene expression in the placenta: maternal stress and epigenetic responses Ciprian P. Gheorghe, Ravi Goyal, Ashwani Mittal and Lawrence D. Longo Int. J. Dev. Biol. (2010) 54: 507-523

Placental metabolic reprogramming: do changes in the mix of energy-generating substrates modulate fetal growth? Nicholas P. Illsley, Isabella Caniggia and Stacy Zamudio Int. J. Dev. Biol. (2010) 54: 409-419

Early expression of axon guidance molecules in the embryonic chick mesencephalon and pretectum Kerry-Lyn Riley, Sarah Gledhill and Frank R. Schubert Int. J. Dev. Biol. (2010) 54: 743-753

A critical role for myoglobin in zebrafish development

Danielle H. Vlecken, Janwillem Testerink, Elisabeth B. Ott, Philippe A. Sakalis, Richard T. Jaspers and Christoph P. Bagowski

Int. J. Dev. Biol. (2009) 53: 517-524

Spatio-temporal expression of a Netrin homolog in the sea urchin Hemicentrotus pulcherrimus (HpNetrin) during serotonergic axon extension Hideki Katow

Int. J. Dev. Biol. (2008) 52: 1077-1088

Analysis of Netrin 1 receptors during inner ear development Tanja Matilainen, Maarja Haugas, Jordan A. Kreidberg and Marjo Salminen Int. J. Dev. Biol. (2007) 51: 409-414

Characterization of Hypoxia induced gene 1: expression during rat Central Nervous System maturation and evidence of antisense RNA expression

Gabriela Bedó, Marcelo Vargas, María-José Ferreiro, Cora Chalar and Daniella Agrati Int. J. Dev. Biol. (2005) 49: 431-436

ISI Impact Factor $(\mathbf{2 0 1 0})=\mathbf{2 . 8 6}$

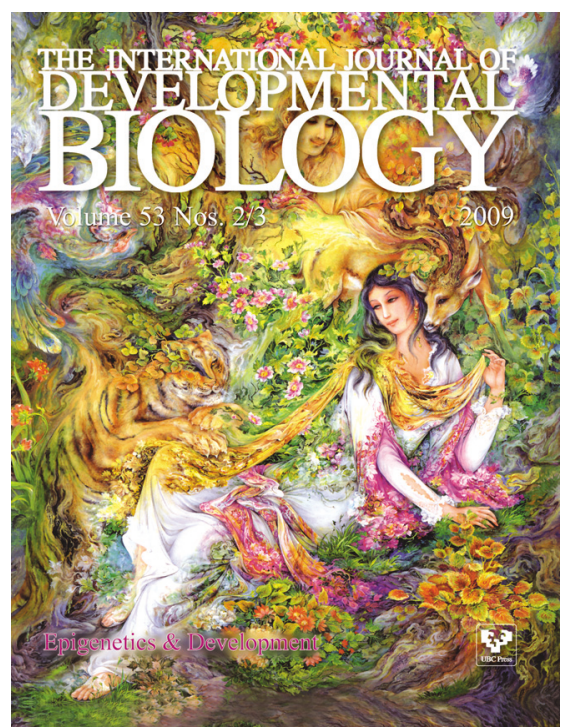

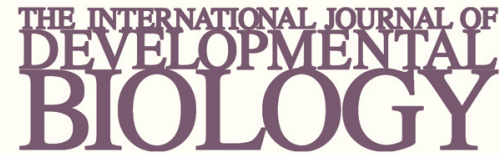

Volume 54 Nos. $6 / 7$
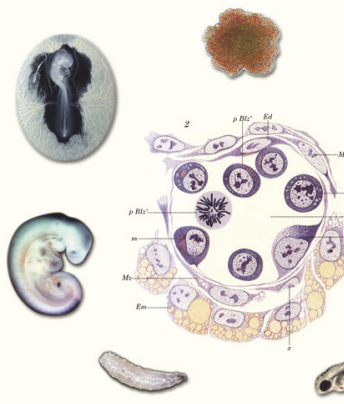

Developmental Hematopoiesis

Special Issue
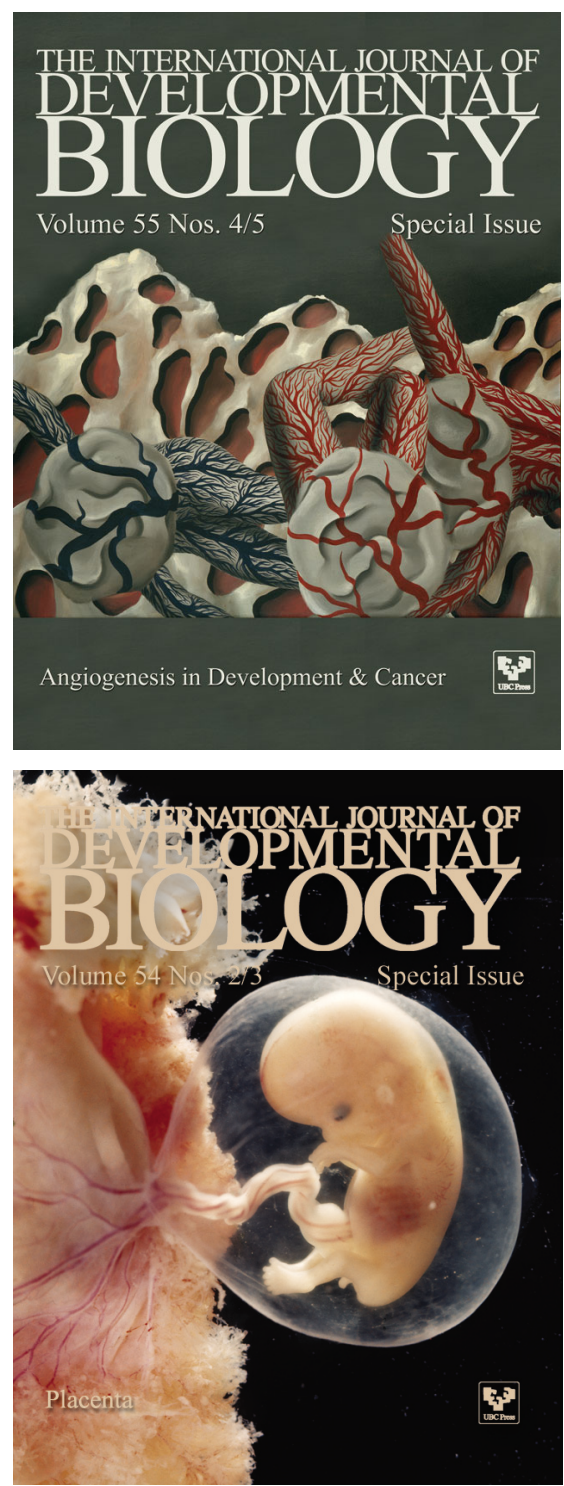